\title{
BMJ Open Predicting death over 8 years in a prospective cohort of HIV-infected women: the Women's Interagency HIV Study
} Deborah R Gustafson, ${ }^{1}$ Quiuh Shi, ${ }^{2}$ Susan Holman, ${ }^{3}$ Howard Minkoff,,${ }^{4,5}$
Mardge H Cohen, ${ }^{6}$ Michael W Plankey, ${ }^{7}$ Richard Havlik, ${ }^{8,9}$ Anjali Sharma, ${ }^{10}$
Stephen Gange,${ }^{11}$ Monica Gandhi,,${ }^{12}$ Joel Milam, ${ }^{13}$ Donald R Hoover ${ }^{14}$
To cite: Gustafson DR, Shi Q, Holman S, et al. Predicting death over 8 years in a prospective cohort of HIV-infected women: the Women's Interagency HIV Study. BMJ Open 2017;7:e013993. doi:10.1136/ bmjopen-2016-013993

- Prepublication history and additional material for this paper are available online. To view these files please visit the journal online (http://dx.doi. org/10.1136/bmjopen-2016013993).

Received 23 August 2016 Revised 27 March 2017 Accepted 5 April 2017
CrossMark

For numbered affiliations see end of article.

Correspondence to Dr. Deborah R Gustafson; deborah.gustafson@downstate. edu

\section{ABSTRACT}

Objectives Predicting mortality in middle-aged HIVinfected (HIV+) women on antiretroviral therapies (ART) is important for understanding the impact of HIV infection. Several health indices have been used to predict mortality in women with HIV infection. We evaluated: (1) an HIV biological index, Veterans Aging Cohort Study (VACS); (2) a physical index, Fried Frailty Index (FFI); and (3) a mental health index, Center for Epidemiologic Studies-Depression (CES-D). Proportional hazards regression analyses were used to predict death and included relevant covariates.

Design Prospective, observational cohort.

Setting Multicentre, across six sites in the USA.

Participants 1385 multirace/ethnic ART-experienced HIV+ women in 2005.

Primary and secondary outcomes All deaths, AIDS deaths and non-AIDS deaths up to $\sim 8$ years from baseline. Results Included together in one model, VACS Index was the dominant, significant independent predictor of all deaths within 3 years $(\mathrm{HR}=2.20,95 \% \mathrm{Cl} 1.83,2.65$, $\left.\chi^{2}=69.04, p<0.0001\right)$, and later than 3 years $(\mathrm{HR}=1.55$, $95 \% \mathrm{Cl} 1.30,1.84, \chi^{2}=23.88, \mathrm{p}<0.0001$ ); followed by FFI within 3 years $\left(\mathrm{HR}=2.06,95 \% \mathrm{Cl} 1.19,3.57, \chi^{2}=6.73\right.$, $\mathrm{p}=0.01)$ and later than 3 years $(\mathrm{HR}=2.43,95 \% \mathrm{Cl} 1.58$, $\left.3.75, \chi^{2}=16.18, p=0.0001\right)$. CES-D score was not independently associated with mortality.

Conclusions and relevance This is the first simultaneous evaluation of three common health indices in HIV+ adults. Indices reflecting physical and biological ageing were associated with death.

\section{INTRODUCTION}

HIV infection continues as a major global health issue affecting approximately 36 million people worldwide. HIV infection has evolved from a fatal infection to a treatable, chronic condition of ageing, ${ }^{12}$ accompanied by multiple morbidities and rising healthcare costs. The North American AIDS Cohort Collaboration on Research and Design observed that life expectancy of HIV-infected $(\mathrm{HIV}+)$ adults increased from 36 to 51 years between 2000 and $2007,{ }^{3}$ primarily due to
Strengths and limitations of this study

Longitudinal cohort study with follow-up of almost 10 years.

- Well-phenotyped White, African-American and Latina HIV-infected women.

- Reputable standardised and validated physical, biological and mental health indices.

- Somewhat limited generalisability since a survivor sample of urban women with strong, consistent research study-related HIV care and social support.

- Health indices and mortality were examined at midlife, a period when risk of death is low.

treatment advances. In 2015, over half of HIV+ Americans are $\geq 50$ years old. ${ }^{3}$ Therefore, HIV infection may prove to represent a modern-day phenomenon of achieving healthy old age accompanied by improved longevity.

Predicting death in chronic HIV infection may assist in the design of interventions to understand, prevent, cure or minimise age-related impairments, improve health and increase lifespan. Several health indices predict death in adults with HIV infectionthe Veterans Aging Cohort Study (VACS) Index; Fried Frailty Index (FFI); and the Center for Epidemiologic Studies-Depression (CES-D) score. These indices represent biological, physical and mental health vulnerabilities that worsen with age. The only HIV-specific mortality index is the VACS Index, which has been reproduced in North American and European patient populations including highly active antiretroviral therapy (HAART) users in the Women's Interagency HIV Study (WIHS).$^{45}$ The VACS Index creates a clinical HIV mortality risk score by summing preassigned points for age, routinely monitored indicators of HIV disease and general 
indicators of organ system function. ${ }^{5}{ }^{6}$ The FFI is most commonly used when describing ageing in both general and HIV+ populations. ${ }^{78}$ Frailty is a common comorbidity of HIV infection, observed even during middle age ${ }^{49}$ The FFI includes measures of gait speed, handgrip strength, body weight loss, physical activity, and exhaustion and predicts death. ${ }^{10-12}$ The CES-D score measures mental health ${ }^{13}$ and has been independently associated with mortality, particularly among women with HIV infection on HAART in the WIHS. ${ }^{4}$

The objective of our analyses was to evaluate, among HIV+ women, the association of the aforementioned, frequently used health indices, VACS, FFI and CES-D, with death (both AIDS related and non-AIDS related). All indices were measured in midlife (average age 39 years) in our analyses and evaluated for prediction of mortality for up to $\sim 8$ years. This follow-up period was further broken down into short-term (within 0-3 years) and long-term ( $>3$ to $\sim 8$ years) deaths, since studies show that prediction of death may vary depending on the exposure being evaluated in relation to more immediate precipitating diseases or conditions versus chronic outcomes.

\section{METHODS}

\section{Study population}

WIHS is a prospective, observational cohort suitable to study the intersection of HIV infection and ageing. WIHS participants enrolled at six sites (Bronx/Manhattan, Brooklyn, Chicago, Los Angeles, San Francisco and Washington, DC); methods and baseline cohort characteristics have been described previously. ${ }^{14}$ Participants have visits every 6 months, which include an extensive face-to-face interview by trained interviewers, medical examinations and laboratory specimen collection. Written informed consent was provided by all WIHS participants via human subject protocols that were approved by institutional review committees at each affiliated institution (Albert Einstein College of Medicine and Montefiore Medical Center Institutional Review Board, \#03-07-174; Cook County Bureau of Health Services Institutional Review Board, \#15-084; Georgetown University Institutional Review Board, Protocol \#1993-077; State University of New York-Downstate Medical Center Institutional Review Board, \#266921; University of California San Francisco Committee on Human Research, \#1003720; and University of Southern California Institutional Review Board, HS-944027.)

Of the HIV+ women actively enrolled in 2005, 1395 completed an assessment of the FFI. Of these, 1385 women were antiretroviral therapy (ART)-experienced and had measures of both VACS Index and CES-D. These women are included in the current analyses.

\section{Inclusion criteria}

Women included in these analyses are HIV+ members of the WIHS cohort who had to have adequately completed all indices (VACS, FFI, CES-D) in 2005 for evaluation in association with mortality.

\section{Primary outcome}

Mortality over the $\sim 8$ years, 2005-2013 (also subcategorised into $0-3$ and $>3$ to $\sim 8$ years), subsequent to measurement of the health indices, was the primary outcome. The US National Death Index identified numbers and causes of death from 1 January 2005 through 31 December 2013. Causes of death were subdivided into AIDS and non-AIDS deaths based on consensus panels comprised of WIHS investigators ${ }^{15}$ (see figure 1). AIDS deaths included: pneumonia, progressive multifocal leukoencephalopathy (PML), pneumocystis pneumonia (PCP), wasting syndrome, central nervous system (CNS) lymphoma, candida, cytomegalovirus (CMV), Cryptococcus, toxoplasmosis, tuberculosis (TB)/mycobacterium, cervical cancer, pulmonary hypertension, dementia/neurologic, renal failure, multiorgan failure and pancreatitis. Non-AIDS deaths included: non-AIDS-related malignancy, gastrointestinal, trauma, drug/alcohol overdose, heart disease, lung disease, liver disease, kidney disease, neurologic/ stroke, haemorrhage, pneumonia, psychiatric, surgical complication or pregnancy complication. For some, cause of death could not be classified as AIDS or non-AIDS, thus the sum of these two subcategories is less that the total number of deaths during the follow-up period.

\section{Primary predictors of death}

There were three primary predictors of interest: VACS Index, FFI and CES-D score. The VACS Index facilitates a mortality risk score created by summing preassigned points for age, routinely monitored indicators of HIV disease (CD4 count and HIV-1 RNA) and viral hepatitis $\mathrm{C}$ infection (HCV); and general indicators of organ system injury including haemoglobin, FIB-4 and estimated glomerular filtration rate, eGFR $(\mathrm{mL} / \mathrm{min})$. We calculated eGFR based on the Chronic Kidney Disease Epidemiology Collaboration (CKD-EPI) equation. ${ }^{16}$ The VACS Index has a maximum score of 164.

The FFI was defined using well-described criteria. ${ }^{7}$ A woman was classified as frail if she exhibited three or more of five characteristics: (1) impaired mobility, (2) reduced grip strength, (3) physical exhaustion, (4) unintentional weight loss and (5) low physical activity. At each site, mobility was measured using a 3-4 m timed gait test, and impaired mobility was defined as the lowest quintile of performance among HIV negatives. Similarly, grip strength was measured using a dominant handheld dynamometer with maximum force; reduced grip strength was the lowest quintile of performance among HIV negatives. Physical exhaustion was a 'Yes' to the question: 'During the past fourweeks, as a result of your physical health, have you had difficulty performing your work or other activities (for example, it took extra efforts)?' Low physical activity was a 'Yes' to 'Does your health now limit you in vigorous activities, such as running, lifting heavy objects, or participating in strenuous sports?' Unintentional weight loss was a 'Yes' to: 'Since your last visit, have 


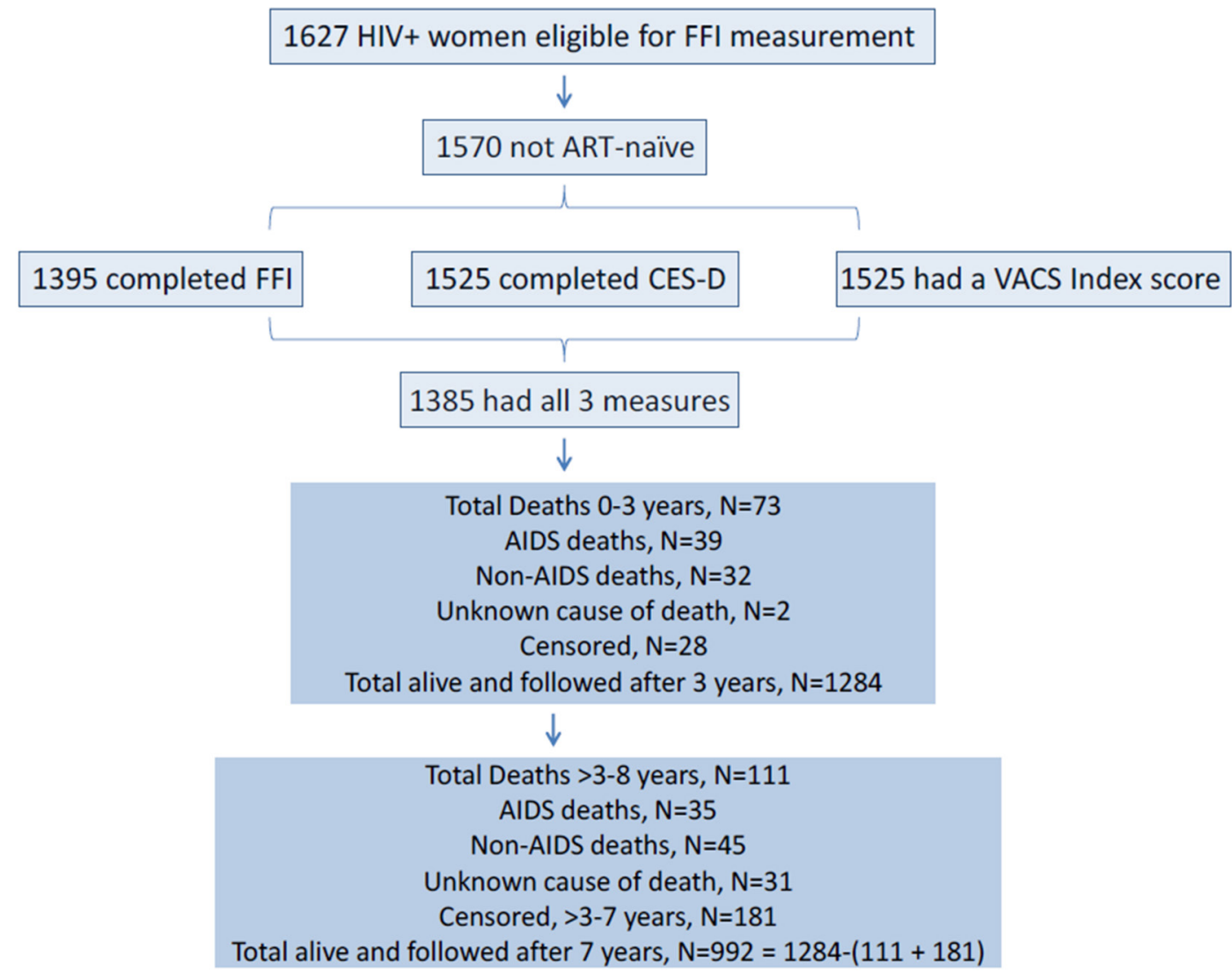

Figure 1 WIHS participants with the VACS Index, FFI and CES-D measured in 2005 and follow-up over approximately 8 years. ART, antiretroviral therapies; CES-D, Center for Epidemiologic Studies-Depression; FFI, Fried Frailty Index; HIV+, HIVinfected; VACS, Veterans Aging Cohort Study; WIHS, Women's Interagency HIV Study.

you had unintentional weight loss of at least 10 pounds?' If at least three components were available, the total out of 3 (or 4) was calculated.

The 20-item CES-D is a depressive symptom screening tool comprised of 20 items and totalling 60 points. A cut point of 16 was used to denote a symptom burden of clinical relevance. ${ }^{17}$

\section{Statistical analyses}

We used single variable and multivariable proportional hazards models to address the questions of which indices (of FFI, VACS or CES-D), when measured at midlife in this sample of HIV+ women, best predicted AIDS, non-AIDS and all deaths. Concordance statistics (C-statistics) were also calculated. The $\mathrm{C}$-statistic for time-to-event outcomes is equivalent to the area under the receiver operating characteristic curve for standard binomial outcomes (range 0.5-1.0). It describes the probability of death associated with a higher health index score or combination of higher health index scores in a randomly selected participant compared with those who do not die. ${ }^{18}$

Covariates found to be significantly associated with mortality were included in these analyses. ${ }^{4}$ These covariates included race/ethnicity, education, smoking, annual income, alcohol drinking, intravenous drug use (IDU) history, body mass index, prior AIDS-defining illness, pneumonia, cancer, diabetes and hypertension. Methods for determining HIV and HCV infection status, AIDS diagnosis, CD4 cell count, HIV viral load, ART use and IDU were described previously. ${ }^{9}$

We refit models (1) restricting follow-up time to the first 3 years after measurement (ie, censoring at 3 years), and (2) starting follow-up time at 3 years after the health indices measurements (ie, truncating prior to 3 years). In addition, the interaction between FFI and CES-D was considered. Results of proportional hazards regression models are presented as HRs with $95 \%$ CI. The $\chi^{2}$ statistic is also presented to facilitate comparison of strength of association between models since the HR scale of each ageing vulnerability index is not the same. Data analyses were accomplished using SAS V.9.4. C-statistics were calculated using STATA V.12.1.

Modified VACS and CES-D Indices. While not reported here, as a sensitivity analysis, we reran the statistical models using a modified VACS Index and a modified CES-D. Our modified VACS Index did not include VACS age groups in the derivation of total points due to the younger age of our sample (VACS Index lowest age group is $<50$ years). Thus, a maximum score of 136 was attainable. We then adjusted for age as age decades that reflected our sample as a separate covariate in multivariate analyses. Our modified CES-D score resulted from excluding two CES-D symptoms that overlap with the FFI. The excluded CES-D 
symptoms were 'this past week I could not get going' (overlaps with low physical activity in the FFI) and 'this past week everything was an effort' (overlaps with exhaustion in the FFI).

\section{RESULTS}

Data were available for all indices on 1385 HIV+ women (average age $42.6 \pm 8.8$ years) who reported history of ART use. The average VACS score was 28.9 \pm 19.4 (possible range $0-164$ ); prevalence of frailty (defined as $\mathrm{FFI}=3-5$ ) was $17.5 \%$; and $39.1 \%$ had a CES-D score of at least 16 points indicating a clinically relevant depressive symptom burden. With regard to calculating the FFI of 1385 women, $1166(84.2 \%)$ had no missing components, $94(6.8 \%)$ had one missing component and 125 (9.0\%) had two missing components. The three indices, as well as individual VACS components, demographic/health behaviour, infectious disease, chronic ageing-related disease variables, number and types of deaths are presented in table 1 . The crude HR $(95 \% \mathrm{CI})$ for all deaths by health indices and demographic/health behaviours, infectious diseases and chronic ageing-related disease variables are presented in table 2.

C-statistics. When evaluated in multivariable models, worse (higher) FFI, VACS and CES-D indices were each significantly associated with a more rapid onset of mortality, additive to higher age and several other covariates based on C-statistics (table 3). As a single index added on to demographics, the VACS Index performed best for all and AIDS deaths; however, the FFI was best for non-AIDS deaths. The C-statistics were qualitatively higher for AIDS deaths, reaching 0.89 with demographics and the VACS Index in the model (and remaining at 0.89 in the full model), compared to the C-statistics for non-AIDs deaths which reached 0.80 with VACS and FFI in the model (and only improving to 0.81 in the full model).

Using multivariable proportional hazards regression models that included all indices, we separately evaluated all deaths up to $\sim 8$ years from baseline (table 4 ) and subdivided by timing of death (short term, $0-3$ years vs long term, $>3$ to $\sim 8$ years from baseline, table 5 ). We also modelled AIDS and non-AIDS deaths separately over the same time periods. Over the entire follow-up period, FFI was a stronger predictor of non-AIDS deaths than was the VACS Index, while VACS was a stronger predictor of AIDS deaths than was FFI. Yet, all HRs were significant for both indices. CES-D was not an independently significant predictor of death.

\section{All deaths}

When considering all deaths, within the first 3 years after baseline measurement (table 5A) the VACS Index was the dominant, significant independent predictor of all deaths $\left(\mathrm{HR}=2.20,95 \%\right.$ CI 1.83, 2.65, $\left.\chi^{2}=69.04, \mathrm{p}<0.0001\right)$, followed by FFI $\left(\mathrm{HR}=2.06,95 \%\right.$ CI $1.19,3.57, \chi^{2}=6.73$, $\mathrm{p}=0.01$ ). For deaths occurring later than 3 years after
Table 1 Baseline characteristics of HIV+ WIHS participants who are not ART naïve

\begin{tabular}{|c|c|}
\hline Variables & $\mathbf{N}(\%)$ or mean $\pm \mathrm{SD}$ \\
\hline \multicolumn{2}{|l|}{ Indices } \\
\hline \multicolumn{2}{|l|}{ FFI } \\
\hline $0-2$ points & $1143(82.5)$ \\
\hline $3-5$ points & $242(17.5)$ \\
\hline \multicolumn{2}{|l|}{ VACS Index score } \\
\hline 0-164 points & $28.9 \pm 19.4$ \\
\hline \multicolumn{2}{|c|}{ CES-D score $>16$ points } \\
\hline No & $844(60.9)$ \\
\hline Yes & 541 (39.1) \\
\hline \multicolumn{2}{|l|}{ Outcomes } \\
\hline \multicolumn{2}{|l|}{ All deaths } \\
\hline 3 years or less & $73(5.3)$ \\
\hline$>3-8$ years & $111(8.0)$ \\
\hline \multicolumn{2}{|l|}{ AIDS deaths* } \\
\hline 3 years or less & $39(2.8)$ \\
\hline$>3-8$ years & $35(2.5)$ \\
\hline \multicolumn{2}{|l|}{ Non-AIDS deaths* } \\
\hline 3 years or less & $32(2.3)$ \\
\hline$>3-8$ years & $45(3.2)$ \\
\hline
\end{tabular}

\section{HIV variables}

CD4 count (cells $/ \mathrm{mm}^{3}$ )

$\begin{array}{lc}>500 & 554(40.0) \\ 200-499 & 614(44.3) \\ <200 & 217(15.7) \\ \begin{array}{l}\text { Viral load (copies/mL) } \\ <500\end{array} & 820(59.2) \\ 500-100000 & 510(36.8) \\ >100000 & 55(4.0) \\ \text { Haemoglobin (g/dL) } & \\ >14 & 209(15.1) \\ 12-13.9 & 743(53.6) \\ 10-11.9 & 362(26.1) \\ <10 & 71(5.1)\end{array}$

FIB4

\begin{tabular}{|c|c|}
\hline$<1.45$ & 1018 (73.5) \\
\hline $1.45-3.25$ & $280(20.2)$ \\
\hline$>3.25$ & 87 (6.3) \\
\hline \multicolumn{2}{|l|}{ eGFR (mL/min) } \\
\hline$>60$ & 1277 (92.2) \\
\hline $45-59.9$ & $71(5.1)$ \\
\hline $30-44.9$ & $15(1.1)$ \\
\hline$<30$ & $22(1.6)$ \\
\hline Hepatitis C coinfection & $298(21.5)$ \\
\hline Demographic variables & \\
\hline
\end{tabular}

Continued 


\begin{tabular}{ll}
\hline Table 1 Continued & \\
\hline Variables & $\mathbf{N}(\%)$ or mean \pm SD \\
\hline $\begin{array}{l}\text { Average age (years, mean } \pm \\
\text { SD) }\end{array}$ & $42.6 \pm 8.8$ \\
\end{tabular}

\section{Race/ethnicity}

\begin{tabular}{|cc|}
\hline White & $324(23.4)$ \\
\hline Black & $806(58.2)$ \\
\hline Others & $255(18.4)$ \\
\hline Education & \\
\hline$<$ High school & $536(38.7)$ \\
\hline High school & $847(61.2)$ \\
\hline Mission & $2(0.1)$ \\
\hline Smoking history & $786(56.8)$ \\
\hline Not current smoking & $599(43.2)$ \\
\hline Current smoking & \\
\hline Income & $669(48.3)$ \\
\hline$<\$ 12000$ & $668(48.2)$ \\
\hline$\geq \$ 12000$ & $48(3.5)$ \\
\hline Missing & \\
\hline Current alcohol drinking & $743(53.6)$ \\
\hline Abstainer/none & $490(35.4)$ \\
\hline Low & $129(9.3)$ \\
\hline Moderate & $23(1.7)$ \\
\hline High & \\
\hline
\end{tabular}

BMI, $\mathrm{kg} / \mathrm{m}^{2}$

\begin{tabular}{lc} 
BMl<30 & $916(66.1)$ \\
BMI’30 (obesity) & $461(33.3)$ \\
Missing & $8(0.6)$ \\
Current ART use & \\
No & $400(28.9)$ \\
Yes (HAART) & $984(71.0)$ \\
Missing & $1(0.1)$ \\
Prior AIDS-defining illness & \\
No & $802(57.9)$ \\
Yes & $583(42.1)$ \\
Injection drug use ever & \\
Yes & $305(22.0)$ \\
No & $1071(77.3)$ \\
\hline Missing & $9(0.6)$ \\
Prior pneumonia & \\
No & $1080(78.0)$ \\
Yes & $305(22.0)$ \\
\hline Current/prior hypertension & \\
\hline No & $964(69.6)$ \\
\hline Yistory of diabetes & $421(30.4)$ \\
\hline
\end{tabular}

Continued
Table 1 Continued

\begin{tabular}{lc}
\hline Variables & N (\%) or mean \pm SD \\
\hline Yes & $190(13.7)$ \\
Prior cancer diagnosis & \\
No & $1220(88.1)$ \\
Yes & $165(11.9)$
\end{tabular}

*For some deaths, cause of death could not be classified as AIDS/ non-AIDS, thus the numbers of AIDS + non-AIDS deaths do not sum to total deaths.

ART, antiretroviral therapies; BMI, body mass index; CES-D, Center for Epidemiologic Studies-Depression; eGFR, estimated glomerular filtration rate; FFI, Fried Frailty Index; HAART, highly active antiretroviral therapy; HIV+, HIV-infected; VACS, Veterans Aging Cohort Study; WIHS, Women's Interagency HIV Study.

baseline measures (table $5 \mathrm{~B}$ ), the relative influence of the VACS Index decreased (HR $=1.55,95 \%$ CI 1.30, 1.84, $\left.\chi^{2}=23.88, \mathrm{p}<0.0001\right)$, and the FFI increased $(\mathrm{HR}=2.43$, $95 \%$ CI $\left.1.58,3.75, \chi^{2}=16.18, \mathrm{p}=0.0001\right)$.

\section{AIDS deaths}

Within 3 years after baseline (table 5C), VACS Index was the only statistically significant independent predictor $\left(\mathrm{HR}=3.33,95 \%\right.$ CI $\left.2.56,4.33, \chi^{2}=80.32, \mathrm{p}<0.0001\right)$ of AIDS deaths; for AIDS death after 3 years (table 5D), both VACS Index (HR=1.75, 95\% CI 1.31, 2.35, $\chi^{2}=13.97$ $\mathrm{p}=0.0002)$ and FFI $\left(\mathrm{HR}=3.38,95 \%\right.$ CI $1.55,7.37, \chi^{2}=9.40$, $\mathrm{p}=0.002)$ were independently significant.

\section{Non-AIDS deaths}

FFI was the most significant predictor of non-AIDS death both within (table $5 \mathrm{E}) \quad(\mathrm{HR}=3.37,95 \%$ CI 1.53 , $\left.7.40, \chi^{2}=9.15, p=0.003\right)$ and later (table $5 \mathrm{~F}$ ) than 3 years post baseline (HR=3.20, 95\% CI 1.66, 6.20, $\chi^{2}=11.95$, $\mathrm{p}=0.0005)$. The VACS Index predicted death later than 3 years $\left(\mathrm{HR}=1.41,95 \%\right.$ CI $\left.1.07,1.86, \chi^{2}=5.84, \mathrm{p}=0.016\right)$, but was not quite as robust as the FFI.

CES-D score was not an independently significant (at $\mathrm{p}<0.05)$ predictor in any AIDS or non-AIDS death model after adjusting for FFI and VACS Index. Also of note, inclusion of ART-naïve participants $(\mathrm{n}=54$, for a total $\mathrm{N}$ of 1439), the use of modified VACS and CES-D Indices or including an interaction term for FFI $\times$ CES-D as described in the Methods section in the regression model did not change our findings.

\section{DISCUSSION}

We systematically evaluated the ability of three common indices representing physical, biological and mental health status to predict mortality in women with HIV infection. These indices-VACS, a biological HIV index; the FFI, a physical index; and the CES-D, a mental health index-were evaluated concurrently in association with mortality over approximately 8 years (and repeated for $0-3$ and $>3$ to $\sim 8$ years) among women with HIV infection. Overall, based on comparative $\chi^{2}$ and C-statistics, 
Table 2 Proportional hazards models of time to all deaths by FFI, VACS Index, CES-D, age group and potential confounders among HIV+ women who are not ART naïve.

\begin{tabular}{|c|c|c|c|}
\hline Variable & Crude HR (95\% CI) & $\chi^{2}$ & p Value \\
\hline \multicolumn{4}{|l|}{ Univariate analyses of indices } \\
\hline VACS score (0-164), per 20 points & 2.20 (1.98 to 2.45$)$ & 214.6 & $<0.0001$ \\
\hline FFI 3-5 vs 0-2 & 3.92 (2.92 to 5.26$)$ & 83.2 & $<0.0001$ \\
\hline CES-D (<16vs > 16) & 2.07 (1.55 to 2.77 ) & 24.0 & $<0.0001$ \\
\hline \multicolumn{4}{|l|}{ Univariate analyses of potential confounders } \\
\hline Age per decade & $1.62(1.38,1.89)$ & 36.14 & $<0.0001$ \\
\hline Race/ethnicity & & 8.95 (2 df) & 0.011 \\
\hline White versus black & $0.55(0.37,0.83)$ & 8.02 & 0.005 \\
\hline Others versus black & $0.74(0.49,1.11)$ & 2.15 & 0.140 \\
\hline Education $\geq$ high school versus $<$ high school & $0.68(0.51,0.90)$ & 6.96 & 0.008 \\
\hline Smoking (current vs no) & $3.41(2.49,4.69)$ & 57.5 & $<0.0001$ \\
\hline Income ( $<\$ 12000$ vs $\geq \$ 12000)$ & $2.03(1.49,2.77)$ & 19.8 & $<0.0001$ \\
\hline Drinking & & 27.25 (3 df) & $<0.0001$ \\
\hline Low versus abstainer/none & $0.59(0.42,0.84)$ & 8.59 & 0.003 \\
\hline Moderate versus abstainer/none & $1.27(0.82,1.98)$ & 1.14 & 0.290 \\
\hline High versus abstainer/none & $3.48(1.76,6.87)$ & 12.9 & 0.0003 \\
\hline BMI, $\mathrm{kg} / \mathrm{m}^{2}(>30$ vs $<30)$ & $0.57(0.41,0.81)$ & 10.2 & 0.001 \\
\hline
\end{tabular}

ART, antiretroviral therapies; BMI, body mass index; CES-D, Center for Epidemiologic Studies-Depression; df, degrees of freedom; FFI, Fried Frailty Index; HIV+, HIV-infected; VACS, Veterans Aging Cohort Study.

the VACS Index was the strongest predictor of death, particularly of AIDS-related deaths and early deaths within 3 years after index assessments. The FFI was additively informative, a better predictor of non-AIDS deaths

Table 3 Concordance statistics from proportional hazards models for health indices used to predict death among HIV+ women who were ART-experienced

\begin{tabular}{|c|c|c|c|}
\hline Variables & All deaths & $\begin{array}{l}\text { AIDS } \\
\text { deaths }\end{array}$ & $\begin{array}{l}\text { Non-AIDS } \\
\text { deaths }\end{array}$ \\
\hline $\begin{array}{l}\text { CES-D + VACS Index } \\
+\mathrm{FFI}+\text { demographics }{ }^{*}\end{array}$ & 0.83 & 0.89 & 0.81 \\
\hline $\begin{array}{l}\text { VACS Index + FFI + } \\
\text { demographics }\end{array}$ & 0.83 & 0.89 & 0.81 \\
\hline $\begin{array}{l}\text { VACS Index + CES-D } \\
+ \text { demographics }\end{array}$ & 0.82 & 0.89 & 0.78 \\
\hline $\begin{array}{l}\mathrm{FFI}+\mathrm{CES}-\mathrm{D}+ \\
\text { demographics }\end{array}$ & 0.78 & 0.80 & 0.80 \\
\hline $\begin{array}{l}\text { VACS Index + } \\
\text { demographics }\end{array}$ & 0.81 & 0.89 & 0.77 \\
\hline FFI + demographics & 0.77 & 0.78 & 0.80 \\
\hline $\begin{array}{l}\text { CES-D + } \\
\text { demographics }\end{array}$ & 0.75 & 0.77 & 0.75 \\
\hline Demographics only* & 0.74 & 0.74 & 0.76 \\
\hline
\end{tabular}

*Demographic variables included were: age, body mass index, race/ethnicity, income, education, cigarette smoking and alcohol use.

ART, antiretroviral therapies; CES-D, Center for Epidemiologic Studies-Depression; FFI, Fried Frailty Index; HIV+, HIV-infected; VACS, Veterans Aging Cohort Study. than the VACS and a relatively more important predictor of deaths from 3 to $\sim 8$ years after index assessments.

First published in 2003, the FFI has been a useful construct by which to predict poor quality of life, cognitive impairment, dementia and death. ${ }^{19}$ Ten years later, the first report on a validated VACS Index specific for those with HIV infection was published. ${ }^{5}$ The VACS Index has, since then, been used to predict mortality in HIV-infected and uninfected populations and has been associated with the FFI. ${ }^{6}$ In the WIHS, the VACS Index and CES-D score considered together have been independently reported to predict mortality over a 5-year period. ${ }^{4}$ Here we show that with addition of the FFI, these relationships change.

The FFI predicts death, particularly among elderly (65 years and older). ${ }^{10}$ More recently, the FFI has been measured in younger adult populations who may be at risk for premature or earlier ageing, such as those with HIV infection. ${ }^{60}$ These studies have shown that adults with HIV infection, even in midlife, experience a prevalence of frailty equivalent to, and greater than, that observed in more elderly adults. ${ }^{49}$ The reason for this early manifestation of the frailty phenotype may be a consequence of HIV infection itself, including suboptimal medication and control of infection early on, comorbid diseases (infectious or non-infectious) $^{4}{ }^{21}$ and/or other lifestyle habits that may be common among those with HIV infection, such as smoking and substance use. ${ }^{11}$ While interesting, FFI fluctuations cannot be addressed in these analyses, but will be in the future with the reinitiation of 


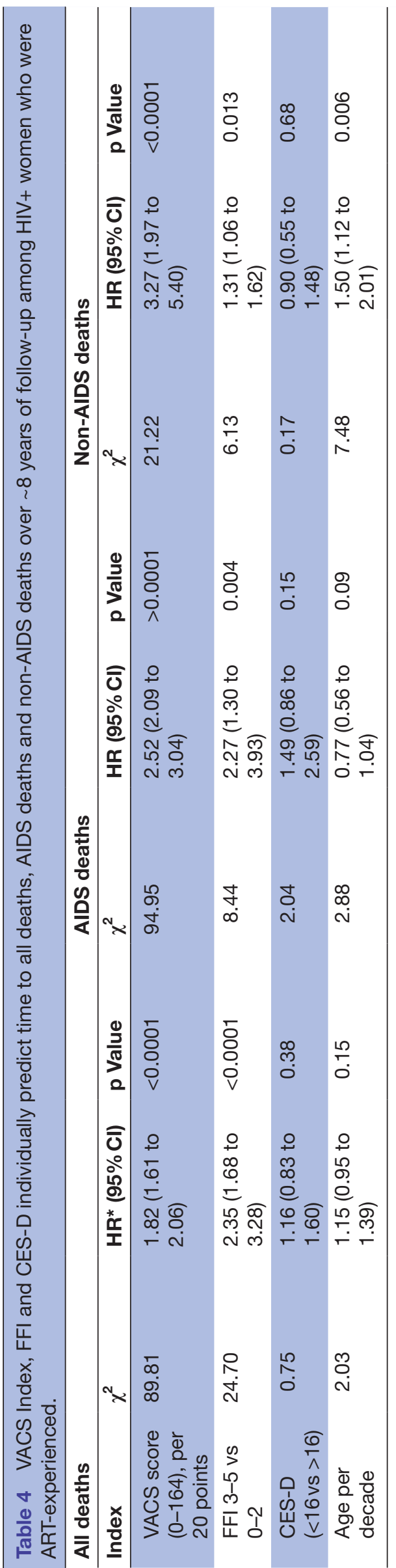

FFI assessments in the WIHS in Fall 2015. As the FFI is a marker of the slower process of physical ageing, it may continue to be more strongly associated with non-AIDS and later deaths as was seen in this analysis.

The CES-D was significantly associated with death in models that did not adjust for VACS and FFI $(\mathrm{HR}=2.07$, $95 \%$ CI 1.55, 2.7, $\mathrm{p}<0.0001, \chi^{2}=24.0$ in table 2); however, it was not associated with death once VACS and FFI indices were included in the same model. Several studies that do not consider FFI and/or VACS, including those from the WIHS, have found CES-D to be a significant 'independent' predictor of mortality. ${ }^{41522-25}$ This study calls into question whether CES-D is a surrogate for other vulnerabilities rather than being independently and causally associated with death. Other studies or analyses of CES-D in relation to death tend to not include other health indices in their models or only include VACS. ${ }^{4}$ It should be noted that modifying the CES-D to exclude two items potentially overlapping with the FFI (low physical activity and exhaustion) did not change the failure of CES-D to be significant in the multivariate models (data not shown).

Evaluating these health indices in middle-aged HIV+ women (the average age of infected women today) is important to understanding the impact of HIV infection on mortality over the life course. This approach has been shown for other diseases of later life. ${ }^{26}$ Midlife physical, biological and/or mental health indicators against the background of HIV infection may be associated with earlier death.

Why are multidimensional health indices associated with mortality in adults with HIV infection? Throughout adult life, HIV infection is synergistic with adverse ageing influences on the immune, vascular, reproductive and central nervous systems, thereby intensifying the ageing process. ${ }^{27}{ }^{28}$ In our previous cross-sectional analysis of the FFI, we showed that the FFI is associated with infectious, demographic, chronic disease, and biological factors, including individual components of the VACS Index, ${ }^{4}$ lending support to this observation.

We chose to assess deaths occurring within 3 years versus those occurring $\geq 3$ years after the indices were measured. Studies in HIV-uninfected populations have shown that deaths occurring within a short period of time (eg, 3 years) tend to be those due to more rapid biological triggers of death such as infections (eg, HIV, pneumonia) or other acute illnesses, while longer term deaths reflect delayed consequences of deteriorating biological and physical health. ${ }^{29}$ Non-AIDS deaths were predicted by FFI, whether those deaths occurred within versus later than 3 years. VACS was more significant for AIDS deaths and deaths occurring within 3 years. Notably, both VACS and FFI were stronger predictors of death (all, AIDS, non-AIDS) than age and other variables considered in the multivariable models reflecting that these indices, more than age, carried the consequences of deteriorating biological and physical health.

Some limitations of our approach may be that the VACS Index was specifically designed and statistically weighted 
Table 5 Multivariable proportional hazards models of time to all deaths, AIDS deaths and non-AIDS deaths within 3 years versus greater than 3 years by VACS Index, FFI, CES-D and age among HIV+ women who were ART-experienced.

\begin{tabular}{|c|c|c|c|c|c|c|}
\hline \multirow[b]{2}{*}{ Variable } & \multicolumn{3}{|c|}{ A. All deaths within 3 years after FFI visit } & \multicolumn{3}{|c|}{ B. All deaths later than 3 years after FFI visit } \\
\hline & $\chi^{2}$ & $\begin{array}{l}\text { Multivariate-adjusted } \\
\mathrm{HR}^{\star}(95 \% \mathrm{Cl})\end{array}$ & p Value & $\chi^{2}$ & $\begin{array}{l}\text { Multivariate-adjusted } \\
\operatorname{HR}^{\star}(95 \% \mathrm{Cl})\end{array}$ & p Value \\
\hline VACS Index per 20 points & 69.04 & 2.20 (1.83 to 2.65$)$ & $<0.0001$ & 23.88 & 1.55 (1.30 to 1.84$)$ & $<0.0001$ \\
\hline FFI (3-5 vs 0-2 points) & 6.73 & 2.06 (1.19 to 3.57$)$ & 0.01 & 16.18 & 2.43 (1.58 to 3.75$)$ & 0.0001 \\
\hline CES-D (<16 vs $\geq 16$ points) & 1.01 & $1.32(0.77$ to 2.28$)$ & 0.31 & 0.11 & 1.07 (0.71 to 1.62$)$ & 0.74 \\
\hline \multirow[t]{3}{*}{ Age per decade } & 0.09 & 1.05 (0.77 to 1.42$)$ & 0.76 & 3.24 & 1.26 (0.98 to 1.61$)$ & 0.07 \\
\hline & \multicolumn{3}{|c|}{$\begin{array}{l}\text { C. AIDS deaths within } 3 \text { years or less after } \\
\text { FFI visit }\end{array}$} & \multicolumn{3}{|c|}{$\begin{array}{l}\text { D. AIDS deaths later than 3years after FFI } \\
\text { visit }\end{array}$} \\
\hline & $\chi^{2}$ & $\begin{array}{l}\text { Multivariate-adjusted } \\
\mathrm{HR}^{\star}(95 \% \mathrm{Cl})\end{array}$ & p Value & $\chi^{2}$ & $\begin{array}{l}\text { Multivariate-adjusted } \\
\mathrm{HR}^{\star}(95 \% \mathrm{Cl})\end{array}$ & p Value \\
\hline VACS Index per 20 points & 80.32 & $3.33(2.56,4.33)$ & 0.0000 & 13.97 & 1.75 (1.31 to 2.35$)$ & 0.0002 \\
\hline FFI (3-5 vs 0-2 points) & 0.88 & $1.45(0.67,3.14)$ & 0.34 & 9.40 & 3.38 (1.55 to 7.37$)$ & 0.002 \\
\hline CES-D ( $<16$ vs $\geq 16$ points) & 1.96 & $1.73(0.80,3.73)$ & 0.17 & 0.81 & $1.43(0.65$ to 3.14$)$ & 0.37 \\
\hline Age per decade & 2.42 & $0.72(0.47,1.09)$ & 0.12 & 0.09 & 0.93 (0.58 to 1.50$)$ & 0.77 \\
\hline
\end{tabular}

\begin{tabular}{|c|c|c|c|c|c|c|}
\hline & \multicolumn{3}{|c|}{$\begin{array}{l}\text { E. Non-AIDS deaths within } 3 \text { years or less } \\
\text { after FFI visit }\end{array}$} & \multicolumn{3}{|c|}{$\begin{array}{l}\text { F. Non-AIDS deaths later than } 3 \text { years after } \\
\text { FFI visit }\end{array}$} \\
\hline & $\chi^{2}$ & $\begin{array}{l}\text { Multivariate-adjusted } \\
\mathrm{HR}^{\star}(95 \% \mathrm{Cl})\end{array}$ & p Value & $\chi^{2}$ & $\begin{array}{l}\text { Multivariate-adjusted } \\
\mathrm{HR}^{\star}(95 \% \mathrm{Cl})\end{array}$ & p Value \\
\hline VACS Index per 20 points & 0.80 & 1.16 (0.83 to 1.62$)$ & 0.37 & 5.84 & $1.41(1.07$ to 1.86$)$ & 0.016 \\
\hline FFI (3-5 vs 0-2 points) & 9.15 & 3.37 (1.53 to 7.40 ) & 0.003 & 11.95 & 3.20 (1.66 to 6.20$)$ & 0.0005 \\
\hline CES-D (<16 vs $\geq 16$ points) & 0.15 & 1.17 (0.54 to 2.54$)$ & 0.70 & 0.60 & 0.77 (0.40 to 1.48$)$ & 0.44 \\
\hline Age per decade & 7.43 & 1.90 (1.20 to 3.02$)$ & 0.006 & 1.44 & 1.26 (0.86 to 1.84$)$ & 0.23 \\
\hline
\end{tabular}

*Multivariate models included race/ethnicity; education less than or equal to versus greater than high school; smoking current versus no; income less than versus greater than or equal to $\$ 12000$ annually; alcohol use: low, moderate or high versus none; and body mass index <30 vs $\geq 30 \mathrm{~kg} / \mathrm{m}^{2}$

ART, antiretroviral therapies; CES-D, Center for Epidemiologic Studies-Depression; FFI, Fried Frailty Index; HIV+, HIV-infected; VACS, Veterans Aging Cohort Study.

to predict mortality in HIV+ persons, and that the FFI was designed to be descriptive of a clinically recognisable phenotype. Therefore, the VACS Index may be expected to have more explanatory power in multivariate analyses of HIV-related survival. Furthermore, other health indices also predict mortality. ${ }^{30}$ The VACS, FFI and CES-D health indices were selected because they are typically reported in the literature as being predictive of death in HIV+ samples. The point of our analyses was not to identify the best mortality index de novo, but rather to systematically compare the three health indices that have been reported in the literature. An additional limitation of these health indices, particularly the FFI, is the blatant lack of standardisation across studies. Our goal in these analyses, as aforementioned, was to harmonise the WIHS FFI with that of another large HIV cohort study in the USA-the Male AIDS Cohort Study. This will facilitate our future of working together and comparing the natural history of frailty among those with HIV infection by sex and gender. Finally, the WIHS is a prospective cohort study of women (and for these analyses, HIV+ women who are ART-experienced), with a defined demographic profile (see table 1). This limits generalisability to other groups with and without HIV infection.
Ageing with HIV infection is associated with geriatric morbidities or syndromes, including frailty and other health indices denoting vulnerability; ${ }^{32}$ however, these ageing morbidities often occur earlier among those with HIV infection compared with uninfected individuals. ${ }^{33-36}$ The question is whether HIV infection leads to more severe ageing phenotypes, or accelerates their onset leading to earlier age of death. ${ }^{37}$ These analyses show that two health indices, the VACS (biological) index and the FFI (physical), independently predict mortality in middleaged women with HIV infection; in particular, VACS predicted AIDS death while FFI predicted non-AIDS death. Inclusion of CES-D, a depressive symptom scale, was not independently informative once both the biological and physical health indices were considered. This is the first published report on the simultaneous evaluation of these important indices in association with mortality in women with HIV infection. These analyses point to the importance of designing interventions to address components of multifaceted indices in the hopes of extending the lifespan of patients living with chronic HIV. 


\section{ACKNOWLEDGEMENTS}

The authors thank the women participating in WIHS for their time, cooperation and support.

\section{Author affiliations}

${ }^{1}$ Department of Neurology, State University of New York-Downstate Medical Center, Brooklyn, New York, USA

${ }^{2}$ School of Health Sciences and Practice, New York Medical College, Valhalla, New York, USA

${ }^{3}$ Department of Medicine, State University of New York-Downstate Medical Center, Brooklyn, New York, USA

${ }^{4}$ Maimonides Medical Center, Brooklyn, New York, USA

${ }^{5}$ Department of Obstetrics and Gynecology, State University of New York-Downstate Medical Center, Brooklyn, New York, USA

${ }^{6}$ Department of Medicine, Stroger Hospital of Cook County Health and Hospital System and Rush University, Chicago, Illinois, USA

${ }^{7}$ Department of Medicine, Division of Infectious Diseases, Georgetown University Medical Center, Washington, DC, USA

${ }^{8}$ AIDS Community Research Initiative of America, New York, New York, USA ${ }^{9}$ Arrow Health, Bethesda, Maryland, USA

${ }^{10}$ Department of Medicine, Albert Einstein College of Medicine, Bronx, New York, USA

${ }^{11}$ Department of Epidemiology, Johns Hopkins Bloomberg School of Public Health,

Baltimore, Maryland, USA

${ }^{12}$ Department of Medicine, University of California, San Francisco, California, USA

${ }^{13}$ Department of Preventive Medicine, University of Southern California, Los Angeles, California, USA

${ }^{14}$ Department of Statistics and Biostatistics and Institute for Health, Health Care Policy and Aging Research, Rutgers the State University of New Jersey, New Brunswick, New Jersey, USA

Contributors All authors contributed to this work. Hypothesis generation and manuscript drafting were led by DRG and DRH; statistical analyses and interpretation was led by DRH and QS; participant recruitment and retention were accomplished by the WIHS Principal Investigators, DRG, HM, MHC, MWP, AS, SG, $M G$, and JM and project staff, SH. Manuscript editing was performed by all.

Funding Data in this manuscript were collected by the Women's Interagency HIV Study (WIHS) Collaborative Study Group with centres (Principal Investigators) at New York City/Bronx Consortium (Kathryn Anastos); Brooklyn, NY (HM, DRG); Washington, DC, Metropolitan Consortium (Mary Young); The Connie Wofsy Study Consortium of Northern California (Ruth Greenblatt); Los Angeles County/Southern California Consortium (Alexandra Levine); Chicago Consortium (MHC); Data Coordinating Center (SG). The WIHS is funded by the National Institute of Allergy and Infectious Diseases (U01-Al-35004, U01-Al-31834, U01-Al-34994, U01-Al-34989, U01-Al-34993 and U01-Al-42590) and by the Eunice Kennedy Shriver National Institute of Child Health and Human Development (U01-HD-32632). The study is cofunded by the National Cancer Institute, the National Institute on Drug Abuse, and the National Institute on Deafness and Other Communication Disorders. Funding is also provided by the National Center for Research Resources (UCSF-CTSI Grant No. UL1 RR024131). Data collection was supported by a dissertation grant through the National Institute of Drug Abuse (1R36DA021104-01). In addition, DRG received support from NIH/NIAID ARRA Supplement No. 54492, Swedish Research Council for Health, Working Life and Welfare (AGECAP 2013-2300) and the State University of New York Research Foundation. The contents of this publication are solely the responsibility of the authors and do not necessarily represent the official views of the National Institutes of Health.

Competing interests None declared.

Ethics approval WIHS is a multicentre study, thus each participating institution.

Provenance and peer review Not commissioned; externally peer reviewed.

Data sharing statement Technical appendix, code books, statistical code and dataset are available at the WIHS Statistical Analysis Center, WD-MAC in Baltimore, MD, USA.

Open Access This is an Open Access article distributed in accordance with the Creative Commons Attribution Non Commercial (CC BY-NC 4.0) license, which permits others to distribute, remix, adapt, build upon this work non-commercially, and license their derivative works on different terms, provided the original work is properly cited and the use is non-commercial. See: http://creativecommons.org/ licenses/by-nc/4.0/ (c) Article author(s) (or their employer(s) unless otherwise stated in the text of the article) 2017. All rights reserved. No commercial use is permitted unless otherwise expressly granted.

\section{REFERENCES}

1. Kirk JB, Goetz MB. Human immunodeficiency virus in an aging population, a complication of success. J Am Geriatr Soc 2009;57:2129-38.

2. Vance DE, McGuinness T, Musgrove K, et al. Successful aging and the epidemiology of HIV. Clin Interv Aging 2011;6:181-92.

3. Samji H, Cescon A, Hogg RS, et al. Closing the gap: increases in life expectancy among treated HIV-positive individuals in the United States and Canada. PLoS One 2013;8:e81355.

4. Cohen MH, Hotton AL, Hershow RC, et al. Gender-related risk factors improve mortality predictive ability of VACS Index among HIV-infected women. J Acquir Immune Defic Syndr 2015;70:538-44.

5. Justice AC, Modur SP, Tate JP, et al. NA-ACCORD and VACS Project Teams. Predictive accuracy of the Veterans Aging Cohort Study index for mortality with HIV infection: a North American cross cohort analysis. J Acquir Immune Defic Syndr 2013;62:149-63.

6. Escota GV, Patel P, Brooks JT, et al. SUN Study Investigators. Short communication: The Veterans Aging Cohort Study Index is an effective tool to assess baseline frailty status in a contemporary cohort of HIV-infected persons. AIDS Res Hum Retroviruses 2015;31:313-7.

7. Fried LP, Tangen CM, Walston J, et al. Cardiovascular Health Study Collaborative Research Group. Frailty in older adults: evidence for a phenotype. J Gerontol A Biol Sci Med Sci 2001;56:M146-M157.

8. Rizzoli R, Reginster JY, Arnal JF, et al. Quality of life in sarcopenia and frailty. Calcif Tissue Int 2013;93:101-20.

9. Terzian AS, Holman S, Nathwani N, et al. Women's Interagency HIV Study. Factors associated with preclinical disability and frailty among HIV-infected and HIV-uninfected women in the era of cART. $J$ Womens Health 2009;18:1965-74.

10. Shamliyan T, Talley KM, Ramakrishnan R, et al. Association of frailty with survival: a systematic literature review. Ageing Res Rev 2013;12:719-36.

11. Piggott DA, Muzaale AD, Mehta SH, et al. Frailty, HIV infection, and mortality in an aging cohort of injection drug users. PLoS One 2013;8:e54910.

12. Ravindrarajah R, Lee DM, Pye SR, et al. European Male Aging Study Group. The ability of three different models of frailty to predict allcause mortality: results from the European Male Aging Study (EMAS). Arch Gerontol Geriatr 2013;57:360-8.

13. Andrew MK, Fisk JD, Rockwood K. Psychological well-being in relation to frailty: a frailty identity crisis? Int Psychogeriatr 2012;24:1347-53.

14. Bacon MC, von Wyl V, Alden C, et al. The Women's Interagency HIV Study: an observational cohort brings clinical sciences to the bench. Clin Diagn Lab Immunol 2005;12:1013-9.

15. Cohen $\mathrm{MH}$, French $\mathrm{AL}$, Benning L, et al. Causes of death among women with human immunodeficiency virus infection in the era of combination antiretroviral therapy. Am J Med 2002;113:91-8.

16. Levey AS, Stevens LA, Schmid CH, et al. A new equation to estimate glomerular filtration rate. Ann Intern Med 2009;150:604-12.

17. Lewinsohn PM, Seeley JR, Roberts RE, et al. Center for Epidemiologic Studies Depression Scale (CES-D) as a screening instrument for depression among community-residing older adults. Psychol Aging 1997;12:277-87.

18. Newson RB. Comparing the predictive powers of survival models using Harrell's C or Somers' D. Stata Journal 2010;10:339-58.

19. Hirsch C, Anderson ML, Newman A, et al. Cardiovascular Health Study Research Group. The association of race with frailty: the cardiovascular health study. Ann Epidemiol 2006;16:545-53.

20. Erlandson KM, Schrack JA, Jankowski CM, et al. Functional impairment, disability, and frailty in adults aging with HIV-infection. Curr HIVIAIDS Rep 2014;11:279-90.

21. Verucchi G, Calza L, Manfredi R, et al. Human immunodeficiency virus and hepatitis $C$ virus coinfection: epidemiology, natural history, therapeutic options and clinical management. Infection 2004;32:33-46.

22. Cook JA, Grey D, Burke J, et al. Depressive symptoms and AIDSrelated mortality among a multisite cohort of HIV-positive women. Am J Public Health 2004;94:1133-40.

23. Coughlin SS. Invited commentary: Prevailing over acquired immune deficiency syndrome and depressive symptoms. Am J Epidemiol 2013;177:126-8. 
24. Farinpour R, Miller EN, Satz P, et al. Psychosocial risk factors of HIV morbidity and mortality: findings from the Multicenter AIDS Cohort Study (MACS). J Clin Exp Neuropsychol 2003;25:654-70.

25. Lyketsos CG, Hoover DR, Guccione M, et al. Depressive symptoms as predictors of medical outcomes in HIV infection. Multicenter AIDS Cohort Study. JAMA 1993;270:2563-7.

26. Ritchie K, Ritchie CW, Yaffe K, et al. Is late-onset Alzheimer's disease really a disease of midlife? Alzheimers Dement 2015;1:122-30.

27. Nguyen N, Holodniy M. HIV infection in the elderly. Clin Interv Aging 2008;3:453-72.

28. Kalayjian RC, Landay A, Pollard RB, et al. Age-related immune dysfunction in health and in human immunodeficiency virus (HIV) disease: association of age and HIV infection with naive CD8+ cell depletion, reduced expression of CD28 on CD8+ cells, and reduced thymic volumes. J Infect Dis 2003;187:1924-33.

29. Gustafson DR, Mazzuco S, Ongaro F, et al. Body mass index, cognition, disability, APOE genotype, and mortality: the "Treviso Longeva" Study. Am J Geriatr Psychiatry 2012;20:594-602.

30. Kulminski AM, Ukraintseva SV, Kulminskaya IV, et al. Cumulative deficits better characterize susceptibility to death in elderly people than phenotypic frailty: lessons from the Cardiovascular Health Study. J Am Geriatr Soc 2008;56:898-903.
31. Theou O, Brothers TD, Mitnitski A, et al. Operationalization of frailty using eight commonly used scales and comparison of their ability to predict all-cause mortality. J Am Geriatr Soc 2013;61:1537-51.

32. Greene M, Covinsky KE, Valcour V, et al. Geriatric syndromes in older HIV-Infected adults. J Acquir Immune Defic Syndr 2015;69:161-7.

33. Gustafson DR, Shi Q, Thurn M, et al. Frailty and constellations of factors in aging HIV-infected and uninfected women--the Women's Interagency HIV Study. J Frailty Aging 2016;5:43-8.

34. Desquilbet L, Jacobson LP, Fried LP, et al. Multicenter AIDS Cohort Study. HIV-1 infection is associated with an earlier occurrence of a phenotype related to frailty. $J$ Gerontol A Biol Sci Med Sci 2007;62:1279-86.

35. Desquilbet L, Jacobson LP, Fried LP, et al. A frailty-related phenotype before HAART initiation as an independent risk factor for AIDS or death after HAART among HIV-infected men. J Gerontol A Biol Sci Med Sci 2011;66:1030-8

36. Desquilbet L, Margolick JB, Fried LP, et al. Relationship between a frailty-related phenotype and progressive deterioration of the immune system in HIV-infected men. J Acquir Immune Defic Syndr 2009;50:299-306.

37. Önen NF, Overton ET. A review of premature frailty in HIV-infected persons; another manifestation of HIV-related accelerated aging. Curr Aging Sci 2011;4:33-41. 